\title{
The Treatment of Polysemy and Homonymy in Monolingual General-purpose Dictionaries with Special Reference to Isichazamazwi SesiNdebele
}

\author{
Eventhough Ndlovu, Department of Language Management and Language \\ Practice, University of the Free State, Bloemfontein, South Africa \\ (ndlovue@ufs.ac.za / evennthough@yahoo.co.uk) \\ and \\ Sanelisiwe Sayi, Department of African Languages and Literature, \\ University of Zimbabwe, Harare, Zimbabwe
}

\begin{abstract}
This article focuses on the treatment of polysemy and homonymy in general-purpose monolingual dictionaries with special reference to Isichazamazwi SesiNdebele. It was found that there are some inconsistencies in the treatment of polysemous and homonymous entries in this dictionary. The article shows that an overreliance on one criterion, particularly etymology, to distinguish polysemy and homonymy is often misleading and unreliable. Polysemy itself has its own inherent complexities, among these being the problem of determining the exact number of meanings of a polysemous lemma. When the meanings of a polysemous lemma are listed, the central or primary meaning, which is not always easily ascertainable, should come first. A holistic approach is proposed to distinguish polysemy and homonymy, which entails the use of the following criteria: etymology, relatedness vs unrelatedness of meaning, componential analysis, the identification of the central or core meaning and the test of ambiguity. Whatever results are obtained from a particular criterion, these findings must be compared with those of other criteria, and verified against native speakers' intuitive knowledge and introspective judgements.
\end{abstract}

Keywords: POLYSEMY, HOMONYMY, METAPHOR, CONCEPTUAL MEANING, ETYMOLOGY, HOMOPHONES, HOMOGRAPHS, LEMMA, SENSE, INTUITION, INTROSPECTION

Opsomming: Die behandeling van polisemie en homonimie in eentalige algemene woordeboeke met spesiale verwysing na Isichazamazwi SesiNdebele. Hierdie artikel fokus op die behandeling van polisemie en homonimie in algemene eentalige woordeboeke met spesiale verwysing na Isichazamazwi SesiNdebele. Daar is vasgestel dat daar ' $n$ aantal inkonsekwensies in die behandeling van poliseme en homonieme inskrywings in hierdie woordeboek is. Die artikel toon dat 'n te groot steun op een kriterium, veral etimologie, om polisemie en homonimie te onderskei, dikwels misleidend en onbetroubaar is. Polisemie self het sy eie inherente gekompliseerdhede waarvan sommige die probleem is om die presiese aantal betekenisse van 'n poliseme lemma te bepaal. Wanneer die betekenisse van 'n poliseme inskrywing gelys 
word, behoort die sentrale of primêre betekenis wat nie altyd maklik bepaalbaar is nie, eerste te kom. 'n Holistiese benadering word voorgestel om polisemie en homonimie te onderskei wat die gebruik van die volgende kriteria behels: etimologie, verwantskap teenoor nieverwantskap van betekenis, die identifikasie van die sentrale of kernbetekenis en die toets van dubbelsinnigheid. Watter resultate van 'n bepaalde kriterium ookal verkry word, hierdie bevindinge moet vergelyk word met daardie van ander kriteria, en uiteindelik geverifieer word met moedertaalsprekers se intuïtiewe kennis en introspektiewe oordeel.

Sleutelwoorde: POLISEMIE, HOMONIMIE, METAFOOR, KONSEPTUELE BETEKENIS, ETIMOLOGIE, HOMOFONE, HOMOGRAWE, LEMMA, BETEKENIS, INTUÏSIE, INTROSPEKSIE

\section{Introduction}

The distinction between polysemy and homonymy is not always clear-cut, therefore remaining a debating-point among linguists and lexicographers. As a result of this debate, a number of criteria have been put forward in an attempt to distinguish these two semantic concepts. However, these criteria have not yielded satisfactory and convincing results. It is against this background that this article proposes a holistic approach in delimiting polysemy and homonymy. It examines the treatment of these two concepts with special reference to the monolingual general-purpose dictionary Isichazamazwi SesiNdebele (2001) (henceforth ISN).

As indicated in the front matter (pp. xxii-xxiii), ISN is based on a corpus, so that the words included and the definitions formulated have been done according to the evidence found there. Because the corpus was built at the same time as the dictionary was compiled, in some cases the corpus was still too small to have been useful. This might be the reason why some words and meanings, especially metaphorical meanings, have not been included in ISN. Being a smaller monolingual general-purpose dictionary, the ISN has mostly treated the central or core meanings of words. However, the corpus was effective in deciding on the most commonly used of two or more synonyms.

The editors of ISN mention in the front matter (pp. xxxv-xxxvi) how homonymous and polysemous words are treated. They do not explain, however, on what grounds they distinguished between the two kinds, treating certain entries as homonymous and others as polysemous. The various criteria used to delimit polysemy and homonymy are therefore explored in this article in an effort to examine how dictionary editors, particularly the ISN editors, treated these concepts. In spite of the following discussions in which words are identified as related, it must be remembered that polysemous words may sometimes, for reasons of surveyability or findability, be treated like homonyms in two or more entries.

The article begins with an overview of polysemy and homonymy and then move on to explore the various criteria that may be used to distinguish them. It concludes with findings and recommendations of how lexicographers should treat polysemy and homonymy in monolingual general-purpose dictionaries. 


\section{Polysemy}

The concept of polysemy involves a number of inherent problems which relate to the difficulty of recognising polysemy, identifying the number of meanings of a polysemous word and dealing with transference of meaning, that is, identifying which is the primary meaning and which is (are) the secondary meaning(s). Linguists and lexicographers seem to agree on what polysemy is. They all define polysemy as a case where the same word has two or more different, but conceptually related meanings or variants of the same meaning (Lyons 1977: 552; Palmer 1981: 101; Hurford and Heasley 1983: 123; Saeed 1997: 64; Zgusta 1971: 61; Jackson 1988: 5; Landau 1984: 100).

A polysemous word has a direct sense from which other senses can, in semantic analysis, be derived by assuming that they are characterised by some added connotation, or by the sense being figurative, or similarly by transference and specialisation (Zgusta 1971: 61). In the case of some highly polysemous words, one of the senses, usually the direct one, is called the dominant. The dominant sense is usually the one which is the first to be thought of by the majority of the speakers of a language if presented with the word out of context (Zgusta 1971: 64).

The meanings attached to a polysemous word are connectable in some way. Such relationships occur in various ways, among others, historically, psychologically and metaphorically (Leech 1974: 228). Two meanings are historically related if they can be traced back to the same source or if the one meaning can be derived from the other (Leech 1974: 228). For example,

(1) iganu (the marula fruit) derives its meaning from the Ndebele word iganu (tan). The Nguni people also relate iganu (a cow with a tan skin colour) to that resembling the colour of the marula fruit.

These meanings of iganu, which are treated as homonyms in ISN are therefore conceptually related in that a marula fruit and a cow of a similar colour are connected with the colour iganu. In ISN iganu (tan) is not entered as a headword, but is listed under Appendix 4 (p. 543) which forms part of the back matter. It should be the primary sense of the pair in example (1), which are its secondary meanings.

(2) The three words phenduka (repent), phenduka (turn around) and phenduka (change life) are also treated as homonyms in ISN.

The etymology of phenduka (repent) can be traced to the verb phenduka (turn around), which is also related to phenduka (change life). Through semantic extension, the primary meaning of phenduka has come to be used for 'repent' in Christian belief. The meanings of these three verbs are conceptually related because they all share the concept of changing focus or direction. However, in ISN they are treated as homonyms and not as the three meanings of a polyse- 
mous word. The primary meaning is carried by phenduka (turn around) which should be the main entry, being sense 1 and cross-referenced to its synonym tshibilika with the other two meanings listed as senses 2 and 3 .

Two or more meanings are psychologically related if present-day users of a language intuitively feel a relationship between them and therefore tend to treat them as different uses of the same word (Leech 1974: 228). The following, for example, are psychologically and historically related:

igola (a wild cat) and igola (a nephew), and

(4) umthanyelo (a sweeping broom of grass) and umthanyelo (a girl who remains with the bride after the marriage ceremony as her helper, especially for sweeping and other household chores).

In the case of igola, the core meaning is that of 'a wild cat' which, through transfer, also came to mean 'a nephew'. A nephew is by descent a child in the uncle's home, who in the patriarchal structure of the Ndebele family, because he is the son of a daughter with a surname from outside, resembles a domestic cat that adopts the traits of a wild cat once it runs away from the home where it was kept. It is a domestic cat, but, like a nephew who cannot claim the inheritance from his uncle, it no longer has legitimate rights. However, in ISN the transferred meaning of igola is not entered.

In the case of umthanyelo, the core meaning relates to a sweeping broom, while as a helper, the girl assists in sweeping and other household chores. Ndebele speakers perceive that the two meanings are conceptually related, because the girl's chores involve using a broom. This is consequently correctly treated as a case of polysemy in ISN.

The secondary meaning(s) of words historically or psychologically connected is (are) related to or derived from the core or central meaning. It starts with observing striking similarities (though not always) that warrant extension and transference of meaning. Words that are etymologically related are one way or another connected in meaning, either by extension or transfer, among others. According to Zgusta (1971: 76), historically related meanings are however not always psychologically related and neither are psychologically related meanings always historically related. Given this fact, it is therefore necessary to adopt a holistic approach for distinguishing polysemy and homonymy in order to ascertain the findings of one criterion in comparison with those of the other criteria.

The tracing of the various ways in which the senses of a polysemous word relate begins with the speakers' feeling or noting of some striking resemblances between objects or beings as far as features or behaviour are concerned. These striking resemblances then lead to these objects or beings being referred to with the same name. Some sort of similarity is the basis of metaphor, though it is not always cases of visible or striking resemblances that cause metaphoric transfer. 
The similarity in a metaphor may be of function, position or many other properties. It does not matter in what direction the first application of a word or the derivation of the literal meaning of a word has taken place.

The word can first apply to humans, animals, plants or objects, e.g. uhlamou (a maize seed) to uhlamvu (a bullet) to uhlamvu (a phoneme), or inhloni (a hedgehog) to inhloni (shyness), and transfer can occur in any order, e.g. iqanda (an egg) to iqanda (a spoiled child), isambane (an antbear) to isambane (a powerful person) or inhloko (an animal head) to inhloko (the head of a family) to inhlo$k o$ (the subject of a sentence). This needs to be borne in mind, especially when establishing the literal and transferred meanings. In ISN the transferred meanings of iqanda (a spoiled child) and isambane (a powerful person) are not included together with the primary meanings of these headwords. The meanings inhloko (an animal head) and inhloko (the head of a family) are correctly treated as polysemous in ISN, but inhloko (the subject of the sentence) which is conceptually related to inhloko (an animal head) is entered as homonymous with it.

Lakoff and Johnson (2003: 3) observe that metaphor is pervasive in everyday life, not just in language, but also in thought, and that metaphorical thought is normal and ubiquitous in our mental life, both conscious and unconscious. They further note that fundamentally metaphors are mechanisms of the mind and that our conceptual system is metaphorical in nature.

Metaphor is defined as a case where a word appears to have both a literal and a transferred meaning (Jackson and Amvela 2000: 59-60). Metaphor as a source of polysemy presents inherent challenges in dealing with polysemy itself and in dealing with both polysemy and homonymy. The major challenges comprise identifying the literal meaning of the polysemous word and telling whether it is a case of polysemy or homonymy.

In cases where meanings of polysemous words relate metaphorically, there is a transfer of meaning. In these cases, the polysemous word has both a literal meaning and the transferred or figurative meaning(s) (Jackson and Amvela 2000: 60). According to the speaker's intuitive knowledge or linguistic competence, it is clear which word has the literal sense. The close relationship between the senses of polysemous words can be illustrated by the following examples. A human or animal has ulimi (a tongue) and then, because of some resemblance with a certain part of a shoe, the human tongue is metaphorically extended to ulimi (the tongue of a shoe). This is given as a qualified entry ulimi lwesicathulo in the ISN. In reality it should be the second sense of a polysemous entry ulimi. Like ulimi (the tongue of a shoe), ulimi (a decorative ornament worn by women around their necks) resembles the shape of the tongue. It is a metaphoric extension of the meaning of the tongue. However, in ISN it is treated as a homonymous entry with ulimi (a tongue). Since gossiping occurs by using the tongue, it is then also called ulimi, the result of a further metaphorical extension. The same is true of the word isandla (hand) whose meaning has been transferred to the habit of stealing. A metaphorical extension has occurred here because stealing is done by the hand; hence a thief has isandla. Furthermore, 
isandla (handwriting) is a metaphorical extension of isandla (hand). However, in ISN these transferred meanings are not included.

Metaphor, being the most familiar kind of meaning transfer, is irregular because it applies to individual lexical items, whereas other types of meaning transfer are more regular because they apply to several members of a specific lexical class (Jackson and Amvela 2000: 60). The words for parts of the body provide a good illustration of metaphor, for example, unyawo (the human foot) to unyawo (the foot of a bed/chair); ikhala (the human nose) to ikhala (the barrel of a rifle); and umlomo (the mouth) to umlomo (the opening of a bottle) to umlomo (the opening of a boil) to umlomo (the habit of provoking others). For the first two examples, the second extended meaning has not been included in ISN. The third example umlomo is accurately treated as a polysemous entry. A second homonymous entry umlomo is given which, however, is also related to meaning 1 of the first entry.

Owing to striking resemblances in terms of shape, position and many other properties between these objects, meaning transfer took place resulting in cases of polysemy. Each of the senses of these examples are related because the meaning of the other is derived from the one carrying the direct sense. The meanings of the latter words in the pairs have been derived through some discernible process of metaphorical connection.

Except for human body parts, animal and plant parts provide further illustrations of metaphor. For example, umthala (the ridge in the paunch of ruminants) to umthala (the white layer or line dissecting the sky at night during or towards the rainy season); ugatsha (the branch of a tree) to ugatsha (a ministry or department); and uphondo (an animal horn) to uphondo (a cow horn formation) to uphondo (a bicycle handle) to uphondo (an instrument for injecting traditional medicine to cure ingubhane (a type of sickness affecting children)).

Native speakers of Ndebele intuitively know to whom or what these words apply first. As indicated earlier, the direction of meaning transfer does not follow one direction. The literal sense can first apply to humans, animals, plants or objects, for example, inja (a dog) to inja (a badly behaved person), intanga (seeds) to intanga (peers), and isivalo (a door) to isivalo (a student who comes last in class position). In other words, it can be from humans to animals, plants and objects or the other way round. This is often overlooked, leading to the misinterpretation of polysemous as homonymous words.

Metaphor is haphazard, not only within a specific language, but also when the use of the same metaphor is compared across languages. This property renders it irregular (Jackson and Amvela 2000: 60). For example, it may seem obvious that head is appropriate to a nail or eye to a needle in English, but although a nail has a head (ikhanda), a needle does not have an eye (ilihlo), but a hole (isikhala) in Ndebele. A river in Ndebele does not have a mouth (umlomo), but a bottle has. These variations show that it is necessary to distinguish polysemy from homonymy in dictionaries. This helps foreign language learners to find particular meanings, since they lack the linguistic competence and 
intuitive sense of native speakers to conceive different senses as connected. However, because of their fuzziness and complexity, a distinction between polysemy and homonymy is also necessary for native speakers.

Polysemy involves a number of inherent problems which include recognising it, stating the exact number of meanings of a polysemous word and identifying the core or central meaning of the polysemous word. This is more difficult in cases where the literal meaning is associated with an object and the transferred one with a human being.

(5) The meaning inja (a badly behaved person) is derived by comparison from the basic meaning inja (a dog).

In ISN the transferred meaning, which is offensive is not included.

(6) Intanga (peers) and intanga (seeds) can serve as an example of a problem in deciding which of the meanings is central.

Many people will question treating intanga (peers) as being the transferred meaning. However, it appears intanga (seeds) is the central meaning which was transferred to indicate 'people of the same age group', resembling seeds of the same size. In ISN, the plural form ontanga (peers) is entered, although the neuter intanga is also commonly used. This is a case of figurative extension.

(7) Regarding isivalo (a door) and isivalo (a student who comes last in class position), the shared element is the idea of closing. Just as a door closes, so the student who comes last closes the order of merit.

In ISN this transferred meaning is not given, but a second entry has been included with a cross-reference. This was unnecessary, because isidikiselo is a synonym of the primary sense of isivalo and should have been included directly after the definition of the main entry.

(8) The words uphondo (an animal horn) and uphondo (a cow horn formation) are conceptually related. The latter is a transferred meaning of the former because it resembles the half-circle shape of the horns of cows.

In ISN the transferred meanings of uphondo (an animal horn) are not included. They both resemble an animal horn in shape: uphondo (a bicycle handle) resembles the shape of cow horns, while uphondo (an instrument for injecting traditional medicine to cure ingubhane) resembles bush buck horns.

These examples reveal the challenges connected with determining polysemy and homonymy, especially if transference of meaning is from objects to humans. The reason is that some native speakers assume that the literal meaning always applies to humans first and the transferred meaning to objects. 


\section{Homonymy}

Homonymy is defined as a case where two or more words have the same phonological shape and pronunciation, but unrelated meanings (Leech 1974: 228; Lyons 1977: 550; Palmer 1981: 100; Hurford and Heasley 1983: 123; Saeed 1997: 64; Zgusta 1971: 74; Landau 1984: 100; Jackson 1988: 4-5; Svensén 2009: 94). Lexicographers and linguists have often tended to confuse homonyms with homographs and homophones, especially with the former. It is therefore necessary to clearly distinguish homonyms from homographs.

Homographs are words which are spelt the same, but have different pronunciations and unrelated meanings (Saeed 1997: 63; Jackson 1988: 4). For example,

(9) íbèlè (sorghum) and íbélè (breast),

(10) impòndò (horns) and impóndò (the old Zimbabwean $£ 1$ (iphawundi); the Zimbabwean \$2), and

(11) bònà (them) and bónà (see).

Homophones are words that are pronounced the same, but have different spellings and unrelated meanings (Saeed 1997: 63; Jackson 1988: 4-5). It appears that homophones such as sight and site, meat and meet, night and knight in English do not exist in Ndebele.

Examples of homonyms, words which are spelt and pronounced the same, but with unrelated meanings, in Ndebele are:

(12) impukane (the house fly) and impukane (the shoulder meat of a dead animal which moves during the skinning process),

(13) ikhabe (an ambidextrous person) and ikhabe (a watermelon),

(14) ifusi (someone born immediately after twins) and ifusi (an abandoned field),

(15) umthombo (malt prepared from sorghum, millet or rapoko for brewing traditional beer) and umthombo (a well), and

umbala (colour) and umbala (a leg).

In ISN examples (12)-(16) are accurately treated as homonyms. There is no historical connection or psychological relatedness inferable between the senses of these examples. In dictionaries, homonyms are accorded separate headword status, whereas a polysemous entry is treated as a single entry with its definitions listed together and with each definition numbered and descending in order of primary to secondary meaning (Landau 1984: 100). Homonyms are part of the macrostructure of the dictionary and polysemy usually affects the microstructure of the dictionary (Landau 1984: 100; Svensén 2009: 96). 


\section{Distinguishing between polysemy and homonymy}

In the compilation of a dictionary, there should be consistency and uniformity in the treatment of polysemous and homonymous lemmas. The lexicographer has to apply uniform principles in deciding what should be entered under one and the same lemma and how lexical items having identical base forms are to be treated (Svensén 2009: 94). The lexicographer should not try to make the single senses more sharply distinguished from each other or try to make different senses more closely related than is indicated by the data (Zgusta 1971: 64).

According to Zgusta (1971: 74), homonymy is founded on the way the speakers understand and interpret the meaning or the senses of identical forms. He argues that homonymy begins at the point when the speakers of a language are unable to conceive different senses as connected. When the single senses of a word lose their connection, the word and its meaning can be split into two. Zgusta deplores it that the only way to determine this is to rely on the subjective interpretation of the speakers. This article proposes a holistic approach that seeks to ascertain the speakers' subjective interpretations. This approach involves that, if the speakers' interpretations corroborate with etymology, relatedness of meaning, componential analysis, the identification of the central or core meaning and the test of ambiguity, their interpretation will then be accepted.

According to Zgusta (1971: 75), the speakers' interpretation very much depends, among others, on their level of education. In dealing with polysemy and homonymy in Ndebele, the level of education indeed matters, especially when relatedness or unrelatedness of meaning is empirically proved through componential analysis. However, in this case a thorough knowledge of the peoples' culture, way of life and history is also indispensable. Most of the polysemous words in Ndebele can best be understood in this context, together with a thorough knowledge of the language, especially language use. Zgusta (1971: 78) contends that, when dealing with polysemy and homonymy, lexicographers will do well to verify their own opinions by testing the intersubjective opinions of speakers of the language who have a reasonably representative level of education and command of the language. Lexicographers will also do well to consider the lexicographic tradition of the language, if there is any. Unfortunately for Ndebele, ISN is a pioneering monolingual general-purpose dictionary.

In addition to what Zgusta suggests, it is also necessary for lexicographers to consult historical sources and works on the culture and tradition of the language, as well as people knowledgeable about Ndebele culture, history, language use and way of life. This will go a long way in exposing lexicographers to a variety of interpretations that will help them to ascertain their findings. For a corpus-based dictionary like the ISN, books on the material culture and interviews with such knowledgeable people should have been included in the corpus. 
However, the distinction between polysemy and homonymy is not always clear-cut. There are instances where it is difficult to decide whether it is a case of polysemy or homonymy. The distinction between polysemy and homonymy is a contentious issue for linguists and lexicographers. However, a number of criteria have been put forward by both linguists and lexicographers in an attempt to delimit them. Among these criteria are the following: etymology, relatedness of meaning, componential analysis, identifying the central or core meaning, and the test of ambiguity.

\section{Etymology}

Etymology comprises a historical approach (Svensén 2009: 96). Two meanings are historically related if they can be traced back to the same source or if the one meaning can be derived from the other (Leech 1974: 228; Lyons 1977: 550; Jackson 1988: 127; Landau 1984: 100; Svensén 2009: 96). According to this criterion, homonyms are known to have developed from what were formally distinct lexemes in earlier stages of a language. If the meanings of an orthographic word can be shown to be derived from a common origin, then this can be treated as a case of polysemy even if the resultant meanings diverge considerably (Jackson 1988: 128). In other words, etymology is based on the notion of historical relatedness (Leech 1974: 228).

Etymology has been relied on by linguists and lexicographers. However, the criterion has a number of limitations which makes it difficult to use as a basis for an argument. Firstly, as Palmer (1981: 102) rightly explicates, the history of a language does not always accurately reflect its present state. History can be misleading, especially in cases where the prime source of information is oral tradition. This is even more problematic in cases where languages with a relatively short tradition of writing are dealt with. However, it is still a difficult task even in languages which have written records dating back hundreds of years. Lyons (1977: 550) notes that in these languages, there are many words about whose historical derivation native and non-native speakers are uncertain. This being the case, etymology proves to be less useful in distinguishing homonymy and polysemy.

Raising similar concerns, Landau (1984: 100) remarks that etymology is an uncertain guide since etymologically disparate words have sometimes evolved associated meanings and historically related words have often developed distinct meanings so that the modern speaker regards them as unrelated, for example, inyanga (the moon), inyanga (a month), and inyanga (a traditional healer). For most Ndebele speakers these are homonyms as reflected in ISN. The same is true of uhlaka (someone who carries the traditional healer's equipment), uhlaka (splints, sticks used to support the joining of broken joints or bones of people or animals; modern-day plaster), uhlaka (a wooden or reed mat used to carry a human corpse for burial) and uhlaka (a small hut partition used for drying maize on the roof of a hut); uhlamvu (a bullet), uhlamvu (a maize 
seed) and uhlamvu (a phoneme); intaba (a mountain) and intaba (a pile of stones placed on a grave); isimbo (an instrument used by traditional healers to dig out their medicine) and isimbo (the payment or token of appreciation given to a traditional healer after a person has been helped or healed); inyoka (a snake), inyoka (ancestral spirits), inyoka (a lazy person) and inyoka (an evil person); uhlanga (a mark that results from a cut made for specific ritual purposes in someone's flesh), uhlanga (a ritualistic way of passing the spirit of witchcraft on to someone by making a cut in the flesh), uhlanga (a tribe) and uhlanga (the central point of an issue); and inkonyane (a newly born calf) and inkonyane (knock-knees).

Etymologically the senses of these pairs are related as those of the latter words in the pairs are derived from those of the former words. The senses of each pair are conceptually and psychologically related. When the holistic approach is used as will be further demonstrated in this article, these entries are seen as polysemous. For some, homonymy occurs when the speakers of a language are unable to conceive different senses as connected. Divergence of sense has been seen as the overriding factor in determining homonymy (Zgusta 1971: 74). However, in each of these cases, there is no certain standard for determining whether the divergence is sufficient to warrant separate headword status as homonyms rather than status as one polysemous entry. This then calls for something more than etymology.

\section{Relatedness vs unrelatedness of meaning}

One of the major criteria used by linguists and lexicographers for distinguishing homonymy and polysemy is relatedness or unrelatedness of meaning. This criterion seems to correlate with the native speakers' feelings that certain meanings are connected or unconnected. It is based on psychological relatedness where native speakers possess the knowledge and intuition that enable them to conceive different senses as connected or unconnected. This is generally based on the notion of linguistic competence which refers to speakers' implicit, internalised knowledge of the rules of their language.

In applying this criterion to draw the distinction between homonymy and polysemy, linguists and lexicographers ask themselves whether any general remarks about the difference of meaning can be made. They ask questions such as: Are regular types of difference found in the meaning of various words? According to this criterion where the differences are regular and to some degree predictable, a case of polysemy rather than homonymy can be ascertained (Palmer 1981: 103).

One of the most familiar relationships between meanings is that of metaphorical or figurative extension (Lyons 1977: 553). In metaphorical or figurative language, the word will have both a literal meaning and one or more transferred or figurative meanings. Lyons (1977: 553) and Palmer (1981: 103) concur that the most striking set of examples is found with words for parts of the 
body. This is shown in the discussion of polysemy and metaphor. Intuitively it is clear enough where the literal sense applies, irrespective of whether the literal sense applies in either direction. Ndebele proverbs reflect that in Ndebele transference of meaning was and still is common from objects to humans.

In cases where metaphor or transference of meaning is involved, speakers, because of their linguistic competence, can, though sometimes with difficulty, discern relatedness of meaning. Generally this criterion is based on the native speakers' judgements. If it is the case that most of them see a metaphorical connection between the different senses of what they take to be the same word, the word in question can then justifiably be marked as a case of polysemy. It is however, necessary to ascertain these findings further by means of other criteria to come to a corroborating conclusion.

Nevertheless, there are several problems associated with this criterion, among them the following: Firstly, relatedness of meaning appears to be a matter of degree. It is uncertain how high or far up the scale words have to be related for them to count as cases of polysemy (Lyons 1977: 552). These degrees of relatedness will in most cases vary from one speaker to another, complicating it even more, since speakers might disagree on similar words.

Secondly, there will always be the problem of pre-theoretical indeterminacy where some native speakers will claim to see a connection between certain words, while others will deny that such relatedness exists (Lyons 1977: 552). In other words, linguistic competence will at times yield conflicting and misleading results, making it difficult to rely on relatedness as a criterion for distinguishing polysemy and homonymy. This again calls for something more than etymology and relatedness of meaning.

Attempts have been made to further explicate the notion of relatedness of meaning in terms of componential analysis of the senses of the lexemes (Lyons 1977: 553). Though componential analysis has its own limitations, the decomposition of the various senses of lexemes does somewhat assist in tracing meaning connections. Componential analysis helps to ascertain the results of etymology, relatedness of meaning and intuition, regardless of the challenges of determining or stating the number of components lexemes must share to count as related in meaning. Once there is a component in common, such lexemes will be considered as related and polysemous, irrespective of it being just one component. Once a commonality has been established, the next step will be to determine relatedness through other criteria. Componential analysis in this proposed approach functions as the empirical test for all the results. For example, it is controversial whether the following words are cases of polysemy or homonymy:

(17) inyanga (the moon), inyanga (a month) and inyanga (a traditional healer).

Inyanga (the moon) carries the central meaning while the other two meanings are derived from it. Inyanga (a month) is determined by the cycles of the moon. The moon serves to illuminate and brighten the earth and the traditional healer 
also clarifies issues in peoples' lives (Sibanda 1998: 137, 173). In meaning inya$n g a$ (a traditional healer) is related to the moon because, just like the moon, it has the components ukuthwasa ${ }^{1}, u k u f a^{2}$ and $u k u k h a n y i s a^{3}$ in common. These shared components between the moon and the traditional healer support the view that this is a case of polysemy. Moreover, the traditional healer's operations are largely determined by the cycles of the moon. On ngelimnyama ${ }^{4}$ the traditional healer does not heal, because his/her powers are believed to be connected to the cycles of the moon. The commonalities between the moon and the traditional healer reveal that the latter meaning was derived from the former; hence this counts as a case of polysemy.

The Ndebele people count time, seasons and months according to the cycles of the moon. The appearance of a new moon marks the beginning of a new month. When the moon appears for the first time, the Ndebeles say inyanga ithwasile (there is a new moon), when the month begins, the Ndebeles say ithwasile (a new month has begun) and when inyanga (a traditional healer) completes his/her training, the Ndebeles say inyanga ithwasile (the traditional healer has graduated). These shared components therefore confirm that these are polysemous words. In ISN, inyanga (the moon), inyanga (a month) and inya$n g a$ (a traditional healer) are treated as homonyms.

The same is the case with

inyoka (snake), inyoka (ancestral spirits), inyoka (a lazy person) and inyoka (an evil person).

These four entries are historically related as the latter derive from the former. In Ndebele culture, ancestral spirits, amadlozi, are referred to as inyoka, because of their links with snakes. People with different ancestral spirits identify with particular snakes and use their bones for divination purposes and as costume accessories. Snakes such as inhlathu (the python), and indlondlo/inyandezulu (the green mamba) are treated as symbols of family ancestral spirits so that when the latter is seen in the yard of a house, sorghum, millet or rapoko is scattered over it as a sign of welcome and appreciation for the divine presence of the living dead in the home. Sorghum, millet and rapoko are food of the ancestral spirits. They are used for brewing traditional beer for rituals associated with ancestral worship and bringing home the living dead. Some ancestral spirits use snake fat, especially that of the python, as a cure for various illnesses. When planning the bringing back home ceremony and the appeasement ceremony, the Ndebele people consider the habits of the snakes (Bozongwana 1983; Ndlovu et al. 1995; Sibanda 1998). They are often heard saying:

Lesi yisikhathi esihle sokubuyisa lokuthethela ngoba inyoka zisathule; zisesephansi azikaqansi izihlahla ziye emqongo.

(This is the right time for thanksgiving and appeasement of the ancestral sprits because the snakes are still underground; they have not climbed up the trees.) 
Snakes are cold-blooded animals that hibernate underground during winter. In view of this explanation, inyoka (snake) and inyoka (ancestral spirits) must be considered as cases of polysemy, yet in ISN they are treated as homonyms. Furthermore, inyoka (a lazy person) and inyoka (an evil person), both meanings not included in ISN, are related to inyoka (a snake). The Ndebele people have a saying that shows the relatedness in meaning of inyoka (a snake) and inyoka (an evil person): Umunt' ololunya lwenyok' egamul' umunt' ingeyikumudla (Someone who is evil like a snake that bites someone, yet is not going to eat him/her). The same relationship exists between inyoka (a snake) and inyoka (a lazy person). When alluding metaphorically to a lazy person, the Ndebele people say: Yinyoka yomuntu kenelisi khon' ukubamb' umthanyelo (Someone is a snake, such a lazy person that he/she cannot even hold a grass broom to sweep), indicating that snakes are considered the laziest reptiles.

This information shows that these words should be treated as polysemes, and not as homonyms. As such knowledge is embedded in the cultural values of the Ndebele people, this should be reflected in the treatment of these words. Béjoint (2000: 124) notes that dictionaries are reflections and guardians of the moral and cultural ideologies of the society. Concurring with Béjoint, Svensén (2009: 1) notes that dictionaries are cultural phenomena and products of the culture in which they have originated.

Other examples of lemmas treated as homonymous in the ISN, yet are in fact polysemous are:

\section{(19) ilanga (the sun) and ilanga (the day).}

The Ndebele people count days according to the cycle of the sun. The rising of the sun marks the beginning of a new day, hence ilanga (the day) was derived from ilanga (the sun). The creation of a separate entry for ilanga (the day) was unnecessary since it is conceptually and semantically related to ilanga (the sun). It should have been entered as sense 2 of ilanga (the sun), then cross-referenced to its synonym $u s u k u$.

(20) inkanku (a type of rain bird) and inkanku (a cow of a colour resembling that of this type of rain bird).

The latter was historically derived from the former because of the resemblance in colour.

(21) isimbo (an instrument used by traditional healers to dig out their medicine) and isimbo (the payment or token of appreciation given to a traditional healer after a person has been helped or healed).

Ndebele speakers feel intuitively that the latter meaning is derived from the former, because the token of appreciation given to the traditional healer relates to the help or healing that comes from the use of this digging instrument.

$$
\text { ugatsha (a branch) and ugatsha (a department). }
$$


The latter is derived from the former because of the relatedness of meaning and resemblance between the two. A branch is part of a tree and a department is part of a larger unit, for example a faculty. Each being a component of something larger, the pair shares a part-whole relationship.

(23) isikhundla (the lair of a hare) and isikhundla (a position or post).

As the lair of a hare, isikhundla, indicates a place of occupation, possession and power for its inhabitant, so isikhundla indicates a post or position of authority and command. Hence these are cases of polysemy.

(24) ingulube (pig) and ingulube (constellation of three stars that follow each other in a linear form during June and July).

The former, ingulube (pig), carries the primary meaning from which the meaning of the latter has been derived: The resemblance lies in the order in which these stars appear, just like wild pigs following one another. When these stars disappear, the one that disappears last is caught up by the other constellation of stars called izinja (dogs), hence the Ndebele proverb Evukela muva ibanjwa yizinja (The pig that follows last is caught by the dogs). This is derived from the wild pigs' habit of following one behind the other. The one that is last is caught by the dogs. The same applies to the star of this constellation called ingulube that disappears last, seemingly caught by the following constellation of stars called izinja. This is also a case of polysemy.

(25) umthala (the ridge in the paunch of ruminants) and umthala (the white layer or line dissecting the sky at night during or towards the rainy season).

Etymologically these two senses are related because the former resembles the latter, acting like the paunch ridge which dissects one of the stomachs of ruminants like the white layer or line dissects the sky; hence they are cases of polysemy, not homonymy as treated in ISN.

ISN also has the entry umthala (a type of grass growing along river banks), which is not in any way related to the first two; hence this is indeed, as ISN's treatment shows, a homonym of the two polysemous senses of umthala.

$$
\text { intaba (mountain) and intaba (pile of stones placed on a grave). }
$$

The meaning of the latter in this pair was derived from the former, because the piled up stones resemble the shape of a mountain, hence these words are etymologically and conceptually related.

(27) uhlaka (someone who carries the traditional healer's equipment), uhlaka (splints, sticks used to support the joining of broken joints or bones of people or animals; modern-day plaster), uhlaka (a wooden or reed mat used to carry a human corpse for burial) and uhlaka (a small hut partition used for drying maize on the roof of a hut). 
Etymologically and psychologically the examples given under (27) share the concept of giving support in some way or another and are therefore cases of polysemy.

(28) uhlanga (a mark that results from a cut made for specific ritual purposes in a person's flesh), uhlanga (a ritualistic way of passing the spirit of witchcraft on to someone by making a cut in the flesh), uhlanga (a tribe) and uhlanga (the central point of an issue).

The meaning of uhlanga (a ritualistic way of passing the spirit of witchcraft on to someone by making a cut in the flesh) derives from uhlanga (a mark that results from a cut made for specific ritual purposes in a person's flesh) because both involve the concept of ukucaba (a ritual cut made for a specific traditional purpose). When witches pass on the spirit of witchcraft to their next of kin, they do so by ukucabela (cutting the flesh of the next of kin and performing some form of ritual to pass on the spirit). The concept of $u k u c a b a$ shared by these words causes them to be classified as polysemous.

Uhlanga (a tribe) and uhlanga (the central point of an issue) are also conceptually related to these two senses of uhlanga. Actually the central meaning is uhlanga (a tribe). It is related to uhlanga (the central point of an issue), both sharing the concept of being the originating source. The relationship between the rituals of cutting one's flesh lies in the fact that they are specifically part of a tribe; they run in the blood, i.e. they are specifically performed on people of the same tribe.

There are, however, two other senses of uhlanga which are not related to the four just discussed. They are: uhlanga (a honeycomb) and uhlanga (a container made of a reed, decorated with beads, worn on the neck and used as an instrument for medicine given to someone having a disease or being possessed to help him/her recover). This is a case of polysemy, because the latter resembles the former in form, especially the bead decoration which looks like a honeycomb. However, in ISN a qualified entry uhlanga lwenyosi (a honeycomb) is given. There is no need for this, because in speech and writing Ndebele speakers do not use it in this form. These two senses of uhlanga should have been treated in a polysemous entry, not as two homonymous entries, the one furthermore qualified.

$$
\text { inkonyane (a newly born calf) and inkonyane (knock-knees). }
$$

All newly born calves have knock-knees and people with a similar characteristic are said to have inkonyane, being like newly born calves. Etymologically and psychologically the two are related through sharing the same concept. In ISN these are treated as separate entries under variant spellings. Some speakers use inkonyana and others say inkonyane when referring to a newly born calf and knock-knees. In defining inkonyane (a newly born calf), ISN should have included inkonyane (knock-knees) as second meaning of a polysemous entry, 
indicating the variant form inkonyana in square brackets directly after the headword.

However, in ISN all these entries are treated as homonymous words yet the application of the criteria of etymology and relatedness of meaning, aided by componential analysis, reveal otherwise. Such a treatment, confusing polysemy and homonymy, causes the dictionary to be less reflective of the Ndebele culture since it is expected of a dictionary to be a guardian of a peoples' culture. It should be a trusted and respected repository of facts about a language and its culture (Béjoint 2000: 124).

\section{Identifying the central or core meaning}

Apart from etymology and relatedness vs unrelatedness of meaning, linguists and lexicographers also identify the core meaning of words in order to ascertain whether they are polysemous or homonymous. This criterion is closely connected with that of relatedness vs unrelatedness of meaning, psychological relatedness and etymology. The criterion of identifying the core or central meaning functions very well in dealing with cases of meaning transfer and metaphor. For example,

(30) inhloni (a hedgehog) and inhloni (shyness) are etymologically and semantically related.

The resemblance in character between the hedgehog and shy people caused the Ndebele to see them as related. The core meaning referring to a hedgehog was transferred to the characteristics of shy people behaving like a hedgehog hiding its head and face when it sees people.

The same can be said of

(31) usungulo (a type of harmless snake) and usungulo (an instrument used for knitting jerseys and an awl used for making or repairing shoes).

These two words are etymologically related. Owing to the resemblance in the shape and size between this type of snake and the knitting instrument, the latter was also called usungulo. This is believed to be the transferred meaning because such instruments were not part of the earlier Ndebele culture. A similar case is

(32) uhlamvu (a bullet), uhlamvu (a maize seed) and uhlamvu (a phoneme).

The Ndebele people saw bullets for the first time during the early days of colonialism, but they already cultivated maize and other cereals, hence the core meaning relates to a maize or other cereal seed. Because of the resemblance between the two, the Ndebele people then derived uhlamou (a bullet) from uhlamvu (a maize seed). Like a maize seed, uhlamvu (a phoneme) refers to a single item within the same family unit. These three senses which should have 
been treated as a polysemous entry, are now given as three homonymous entries in ISN.

All these examples show how observant the Ndebeles were and still are of the habits of birds, animals, people and nature, as further confirmed by the many proverbs they have. Polysemy provides a look into the culture, history, religion, philosophy and way of life of the speakers of a language. This confirms the idea that humans do most of their speaking in metaphors.

\section{The test of ambiguity}

Finally, linguists and lexicographers also use the test of ambiguity to delimit polysemy and homonymy. According to this criterion, homonyms are clearly ambiguous (Palmer 1981: 105). Hurford and Heasley's (1983: 123) definition of homonymy reveals this perception. In defining homonymy, they indicate that it also involves ambiguity:

A case of HOMONYMY is one of an ambiguous word, whose different senses are far apart from each other and not obviously related to each other in any way.

This definition contains the misconception that homonyms are the only ambiguous words. However, this is not always the case since instances of polysemy yield equally ambiguous sentences. To further support the view that polysemous words also ambiguate sentences, most lexicographers contend that polysemous words should be avoided in definitions since they ambiguate the definitions (Svensén 1993; Landau 1984; Ndlovu 2009). Svensén (1993: 119) notes:

Using near synonyms is entirely valid when the need for semantic precision is not too great. One has to be on guard against synonyms that are polysemous since they ambiguate definitions.

This observation can be illustrated by the following two ISN definitions which Ndlovu (2009: 79) identified as ambiguous because of their use of polysemous words. For example,

(33) amachaphaza [amachaphazi] bz 6. Izibungwana ezimhlophe ezingakabi zinyosi ngamachaphaza.

In this definition, izibungwana is polysemous, thus ambiguating the definition. It can be interpreted to mean either the early stages of an insect's development or small insects (in the diminutive sense), which is the primary meaning of izibungwana. Apart from being an illustration of a headword that is defined using a polysemous word, amachaphaza (bee larvae) and amachaphaza (a green, not fully ripe maize cob) are other examples of entries wrongly treated in ISN as homonymous. There are some resemblances between these two: they are both white in colour, and, when being eaten, they both burst (kuthi patsha pa- 
tsha $)^{5}$, producing a white milky liquid. Because of these resemblances, the secondary meaning of amachaphaza (a green, not fully ripe maize cob) was derived from the core meaning of bee larvae.

Another ISN definition that uses a polysemous word is that of ishinga (rascal) which is treated as follows:

(34) ishinga bz 5. Ishinga ngumuntu ongezwayo. FAN ihlongandlebe.

The use of the polysemous word ongezwayo ambiguates the definition. Ongezwayo can be interpreted in two ways, meaning either someone who is naughty or stubborn (isiqholo) and/or someone who is deaf (isacuthe), which is the primary sense of ukungezwa.

When the test of ambiguity is borne in mind, it therefore becomes clear that this cannot be relied on since both polysemy and homonymy can yield ambiguous sentences, as illustrated by the following:

\section{Inyanga ifile.}

Example (35), which is a case of polysemy can be interpreted to mean that either the last quarter of the moon has disappeared or the traditional healer has passed away.

(36) UDojize ulombala omuhle.

Example (36), which is a case of homonymy can be interpreted to mean either that Dojiwe has a beautiful complexion or that Dojiwe has gorgeous legs.

\section{Conclusion}

In the foregoing discussion, it has been observed that ISN treated some polysemous words as homonymous. An application of the holistic approach to the words identified as homonymous, reveals that they are in fact polysemous. It has further been observed that these criteria indicate that saying words are etymologically related means that speakers have noted relatedness in meaning. By using componential analysis, psychological relatedness of meaning can be empirically proven.

In spite of the fact that polysemy and homonymy are often difficult to differentiate, lexicographers must study them from the point of view not only of "pure" semantics by analysing the lexical meaning of isolated words, but also of the cultural context of the language in question. A deeper understanding of the culture to which the language belongs will yield valuable results. A thorough knowledge of the language, especially as far as idiomatic usage is concerned, is also indispensable for a successful delimitation of polysemy and homonymy. This will guard lexicographers against interpreting some phenomena as indications of polysemy or homonymy while they are not. The inconsistent treatment of polysemy and homonymy in ISN reflects the problematic nature of 
attempting to distinguish polysemy and homonymy. It, however, compromises the dictionary's value of being a guardian of a peoples' culture and a trusted and respected repository of facts about a language and its culture.

\section{Endnotes}

1. Ukuthwasa in reference to the moon indicates that there is a new moon and for the traditional healer it means he/she has completed training as a traditional healer.

2. Ukufa in reference to the moon indicates the period when the last quarter of the moon disappears to the time before its reappearance as a new moon and for the traditional healer it means he/she is dead.

3. Ukukhanyisa in reference to the moon indicates that it gives light and for the traditional healer it means he/she makes issues clear; he/she discerns.

4. Elimnyama refers to the day when the last quarter of the moon disappears. During this day Ndebele people do not wash their bodies after sunset because it is believed that bathing after sunset on this day will cause bad luck for the person who disobeys this belief.

5. Patsha is an ideophone of bursting under pressure (as of a ripe fruit when stepped on).

\section{References}

Béjoint, H. 2000. Modern Lexicography: An Introduction. Oxford: Oxford University Press.

Bozongwana, W. 1983. Ndebele Religion and Customs. Gweru: Mambo Press in Association with the Literature Bureau.

Hadebe, S. et al. (Eds.). 2001. Isichazamazwi SesiNdebele. Harare: College Press.

Hurford, J.R. and B. Heasley. 1983. Semantics: A Coursebook. Cambridge: Cambridge University Press.

Jackson, H. 1988. Words and their Meaning. London/New York: Longman.

Jackson, H. and E.Z. Amvela. 2000. Words, Meaning and Vocabulary. London/New York: Continuum.

Lakoff, G. and M. Johnson. 2003. Metaphors we Live by. Chicago: Chicago University Press.

Landau, S.I. 1984. Dictionaries: The Art and Craft of Lexicography. New York: Charles Scribner's Sons.

Leech, G.N. 1974. Semantics. Harmondsworth: Penguin Books.

Lyons, J. 1977. Semantics 2. Cambridge: Cambridge University Press.

Ndlovu, E. 2009. Sense Relations in the Treatment of Meaning in Isichazamazwi SesiNdebele. Lexikos 19 Supplement: 71-85.

Ndlovu, T.M. et al. 1995. Imikhuba Lamasiko AmaNdebele. Gweru: Mambo Press

Palmer, F.R. 1981. Semantics. Cambridge: Cambridge University Press.

Saeed, J.I. 1997. Semantics. Oxford: Blackwell Publishers.

Sibanda, J. 1998. Isikithi. Harare: College Press.

Svensén, B. 1993. Practical Lexicography: Principles and Methods of Dictionary-Making. Oxford/New York: Oxford University Press.

Svensén, B. 2009. A Handbook of Lexicography: The Theory and Practice of Dictionary-Making. Cambridge: Cambridge University Press.

Zgusta, L. 1971. Manual of Lexicography. The Hague/Paris: Mouton. 